\title{
Relation of Oxidative Stress and Impaired Fibrinolysis with HDL Biogenesis in Indonesian Men with Metabolic Syndrome
}

\author{
Ida Paulina Sormin, ${ }^{1,2}$ Widjaja Lukito, ${ }^{3}$ Andy Wijaya ${ }^{1,2}$, Suryani As'ad ${ }^{1}$
}

'Postgraduate Doctoral Programme, Faculty of Medicine, University of Hassanuddin, Makassar ${ }^{2}$ Prodia Clinical Laboratory, Jakarta

${ }^{3}$ SEAMEO-TROPMED Regional Center for Community Nutrition, Faculty of Medicine, University of Indonesia, Jakarta

\section{Abstract}

ACKGROUND: Biogenesis of HDL involves factors that regulate the synthesis, intravascular remodeling, and catabolism of HDL. Disturbance of these factors can lead to low concentration of HDL-C. Metabolic syndrome (MetS) is characterized by low concentration of high-density lipoprotein cholesterol (HDL-C). In MetS occur several pathological conditions including oxidative stress and impaired fibrinolysis, which contribute to the risk of atherosclerosis process. The correlation between oxidative stress and impaired fibrinolysis with HDL biogenesis dysfunction and its correlation with low concentration of HDL-C has not been well understood and therefore needs to be further investigated.

METHODS: This study was an observational study with crosssectional design, involving 163 adult men, aged 25-60 years with metabolic syndrome (IDF criteria, 2005). Concentration of apoA-1, prebeta-1 HDL, CETP, F2-isoprostan, PAI-1, and HDL-C were measured. The apo A1/HDL ratio indicated HDL maturation, whereas the CETP/HDL-C and CETP/TG ratios indicated HDL catabolism.

RESULTS: The study showed that there were a positive correlation between PAI-1 with apoA1/HDL-C ratios (rs= $0.226, p=0.005$ ) and a negative correlation with the CETP/ TG ratios ( $\mathrm{rs}=-0.215, \mathrm{p}=0.007$ ), whereas $\mathrm{F} 2$-isoprostan did not have correlation with HDL biogenesis factors.

CONCLUSIONS: We concluded that there was correlation between impaired fibrinolysis with decreased HDL maturation and there was increased HDL catabolism leading to low HDL-C concentration in men with metabolic syndrome.
KEYWORDS: F2-isoprostan, PAI-1, apoA-1, prebeta-1 HDL, CETP, metabolic syndrome.

\section{Introduction}

HDL-C has an important anti-atherogenic role through reversed cholesterol transport (RCT) by stimulating cholesterol efflux from the peripheral tissues to the liver to be excreted through the gall bladder. The process of HDL biogenesis includes HDL maturation and catabolism, which involves many factors, among others: apo AI, prebeta-1 HDL, and cholesteryl ester transfer protein (CETP) $(1,2)$. Several epidemiological studies have indicated a close relationship between the decrease in high density lipoprotein-cholesterol HDL-C concentrations with coronary heart disease (CHD). More than $40 \%$ of patients with myocardial infarction had low plasma HDL-C concentrations. The Cardiovascular Munster Heart Study has found that the relative risk of $\mathrm{CHD}$ was six times higher in patients with HDL-C concentration $<35 \mathrm{mg} / \mathrm{dL}$ as compared to those with HDL-C concentrations $\geq 35 \mathrm{mg} / \mathrm{dL}$ (3). The National Cholesterol Education Program-Adult Treatment Panel III (NCEP-ATP III) has determined that concentration of $\mathrm{HDL}-\mathrm{C}>40 \mathrm{mg} / \mathrm{dL}$ in men and $>50 \mathrm{mg} / \mathrm{dL}$ in women as therapeutic targets (1).

Low level of high density lipoprotein cholesterol (HDL-C) often accompanies patients with MetS, which may play an important role in the development of coronary heart disease (CHD). Several pathological conditions in MetS include oxidative stress and impaired fibrinolysis, which contribute to the risk of atherosclerosis $(4,5,6)$. Disturbance of HDL biogenesis 
factors causes low HDL-C concentration (1).

Metabolic syndrome (MetS) plays a key role as the trigger of the global pandemic of type 2 diabetes mellitus (DM) and cardiovascular disease. Globally, the incidence of MetS is increasing rapidly. Prevalence of MetS in the world based on epidemiological data was $20-25 \%$. Subjects with MetS are 2-3 times more likely to have a heart attack or stroke as compared to normal subjects. Prevalence of MetS in Indonesia also continues to increase along with changes in its inhabitants' lifestyle. Survey Kesehatan Rumah Tangga (SKRT) in 2004 indicated the prevalence of obesity was about $19 \%$ (Body mass index $>25 \mathrm{~kg} / \mathrm{m}^{2}$ ) (7).

There is a significant negative correlation between HDL-C with BMI, waist circumference, triglycerides, insulin and PAI-1 (6). Tawakol has reported that in individuals with a high concentration of PAI-1 has low concentrations of HDL-C and apoA-1 (8). Decrease in the antioxidant activity of small dense HDL subfraction population was correlated with oxidative stress and insulin resistance (9).

Previous studies have shown that there is a correlation between oxidative stress and impaired fibrinolysis with low HDL-C concentrations, but the exact mechanisms that affect HDL biogenesis have not yet been clarified. Thus this study aimed to find out the relationship between oxidative stress and impaired fibrinolysis with impaired HDL biogenesis that cause low HDL-C concentration. Understanding of the relationship between oxidative stress and impaired fibrinolysis with HDL biogenesis factors in MetS is interesting to be further developed, and this may be used as the basis for developing strategies to increase HDL-C concentration.

\section{Methods}

This study conducted an observational study with crosssectional design, done at Prodia Clinical Laboratory, Jakarta, from June 2008 to April 2009. The study proposal and protocol were approved by the Health Research Ethics Committee of the Faculty of Medicine, University of Hasanuddin, Makassar, Indonesia.

One hundred and sixty three (163) adult men with apparent metabolic syndrome (MetS), aged 25-60, were involved in this study. Subjects in the MetS category met the International Diabetes Federation (IDF) criteria for MetS (10): central obesity (waist circumference (WC) $\geq 90 \mathrm{~cm}$ ) with two of the other four clinical indicators, triglycerides $\geq 150 \mathrm{mg} / \mathrm{dL}, \mathrm{HDL}-\mathrm{C}<40 \mathrm{mg} / \mathrm{dL}$, systolic blood pressure $(\mathrm{SBP}) \geq 130 \mathrm{mmHg}$ or diastolic blood pressure $(\mathrm{DBP}) \geq$ $85 \mathrm{mmHg}$, fasting blood glucose (FBG) $\geq 100 \mathrm{mg} / \mathrm{dL}$. Subjects who had liver and/or kidney dysfunction (as justified by serum aspartate amino transferase (AST) > $66 \mathrm{mg} / \mathrm{dL}$, serum alanine amino transferase (ALT) $>100$ $\mathrm{mg} / \mathrm{dL}$, and/or serum creatinine $>1.6 \mathrm{mg} / \mathrm{dL})(11,12)$, had been treated with medication for diabetes mellitus and hypertension, had been treated with lipid-lowering drugs in the last 3 weeks, were excluded from the study. Data collected were height, weight, waist circumference, blood pressure, smoking habit, exercise, alcohol consumption, and medications. All subjects received both written and oral information regarding the study and gave an informed consent prior to commencement of the study.

Blood samples were collected in the morning from the ante-cubital vein using vacutainers after 12 -hour overnight fasting for measurements of serum HDL-C, triglycerides, glucose, AST, ALT, total bilirubin, direct bilirubin, creatinine, apoA-1, prebeta-1 HDL, CETP, F2-isoprostane, and PAI-1 concentrations. Serums were separated from the whole bloods after centrifugation and immediately kept at a temperature in accordance with requirements of each assay parameter.

Blood specimens for prebeta-1 HDL analysis were collected in EDTA vacutainers. The blood was immediately centrifuged to obtain plasma. The plasma specimens were then diluted with the stabilization buffer within 6 hours after collection. During the course of this process, the specimens were kept in ice. The diluted specimens were stored at $-70^{\circ} \mathrm{C}$ until the assays were done.

Serum HDL-C concentrations were measured using the homogeneous enzymatic method and reagent Cholestest N HDL. Serum apoA-1 concentration was measured using immuno-turbidimetry method with ApoA-1 Auto-N "DAIICHI" ${ }^{8}$ reagent kit, Prebeta-1 HDL and CETP concentrations were measured using a researchbased enzyme-linked immunosorbent (ELISA) method with "Pre- $\beta$ 1-HDL" ELISA DAIICHI and CETP ELISADAIICHI reagent kits respectively (SEKISUI Medical Co Ltd, Tokyo, Japan). F2-isoprostane concentration was measured using an enzyme-linked immunosorbent (ELISA) method with 15-Isoprostane F2t ELISA reagent kit (Oxford Biomedical Research, Inc. Oxford, USA). PAI-1 concentration was measured using an enzyme-linked immunosorbent (ELISA) method with TECHNOZYM ${ }^{\circledR}$ PAI-1 antigen ELISA reagent kit (Technoclone $\mathrm{GmbH}$, Vienna, Austria).

The apoA-1/HDL-C ratio was used as indicator of HDL maturation, whereas the CETP/HDL-C and CETP/ TG ratios were used as indicator of HDL catabolism. 
Statistical analyses were performed with SPSS for Windows version 13.0 software (SPSS Inc., Chicago, IL, USA). Distributions of continuous variables were assessed for normality using the Kolmogorov-Smirnov test. Univariate analysis was performed to calculate means and standard deviations. T-test was applied to compare means of variables between subjects with HDL-C concentration $\geq 40 \mathrm{mg} / \mathrm{dL}$ and HDL-C concentration < $40 \mathrm{mg} / \mathrm{dL}$. We performed bivariate correlation analysis to determine correlations between independent variables (F2-isoprostane, PAI-1, apoA-1/HDL-C, CETP/HDL-C and CETP/TG ratios) with dependent variables (apoA-1, prebeta-1 HDL, and CETP). Results were narrated and explained with tables and graphics. For statistical test, we used $5 \%$ to define the level of significance.

\section{Results}

Table 1 describes basic clinical and biochemical characteristics of the subjects, by HDL-C category (between subjects with HDL-C concentration $\geq 40 \mathrm{mg} / \mathrm{dL}$ and HDL-C concentration $<40 \mathrm{mg} / \mathrm{dL}$ ). No subjects were identified with liver and kidney diseases. Our data revealed significant differences in body mass index (BMI), SBP, DBP, FBG, apo A1, prebeta-1 HDL, apoA-1/HDL-C ratio, CETP/HDL-C ratio. Subjects with HDL-C concentrations $<40 \mathrm{mg} / \mathrm{dL}$ had higher apoA-1/HDL-C and CETP/HDL-C ratios than subjects with $\mathrm{HDL}-\mathrm{C} \geq 40$ concentrations, whereas subjects with HDL-C concentrations $<40 \mathrm{mg} / \mathrm{dL}$ had lower apoA-1, and prebeta-1 HDL than subjects with HDL-C $\geq 40$ concentration.

Table 1. Basic clinical, anthropometric and biochemical charateristics of subjects based on HDL-C concentration groups

\begin{tabular}{|c|c|c|c|c|c|}
\hline \multirow{2}{*}{ Variable } & \multicolumn{2}{|c|}{$\mathrm{HDL} \geq 40 \mathrm{mg} / \mathrm{dL}$} & \multicolumn{2}{|c|}{$\mathrm{HDL}<40 \mathrm{mg} / \mathrm{dL}$} & \multirow{2}{*}{$p$} \\
\hline & Means & SD & Means & SD & \\
\hline $\mathrm{N}$ & 49 & & 114 & & \\
\hline Age $(\text { year })^{1}$ & 42.7 & 1.3 & 41.2 & 0.7 & 0.290 \\
\hline \multicolumn{6}{|c|}{ Anthropometric and clinical variables } \\
\hline WC $(\mathrm{cm})$ & 99.5 & 7.5 & 101.1 & 9.0 & 0.17 \\
\hline BMI $\left(\mathrm{kg} / \mathrm{m}^{2}\right)^{1}$ & 28.2 & 3.3 & 29.8 & 4.3 & 0.021 \\
\hline $\mathrm{SBP}(\mathrm{mmHg})$ & 126.7 & 15.0 & 120.7 & 18.7 & 0.006 \\
\hline $\mathrm{DBP}(\mathrm{mmHg})$ & 86.6 & 11.8 & 80.9 & 12.4 & 0.002 \\
\hline \multicolumn{6}{|l|}{ Biochemical variables } \\
\hline $\mathrm{FBG}(\mathrm{mg} / \mathrm{dL})$ & 111.5 & 31.7 & 99.6 & 26.0 & $<0.001$ \\
\hline Triglycerides (mg/dL) & 223.8 & 106.1 & 221.3 & 105.5 & 0.776 \\
\hline $\mathrm{HDL}-\mathrm{C}(\mathrm{mg} / \mathrm{dL})$ & 44.8 & 5.5 & 35.1 & 3.25 & $<0.001$ \\
\hline ApoA-1 $(\mathrm{mg} / \mathrm{dL})^{1}$ & 134.3 & 12.5 & 113.2 & 9.6 & $<0.001$ \\
\hline Prebeta-1 HDL (mg/dL) & 23.5 & 25.9 & 15.0 & 5.4 & 0.001 \\
\hline CETP $(\mu \mathrm{g} / \mathrm{dL})^{1}$ & 2.93 & 0.58 & 2.93 & 0.50 & 0.979 \\
\hline PAl-1 (ng/ml) & 37.91 & 21.17 & 38.75 & 24.90 & 0.864 \\
\hline F2-Isoprostan (ng/ml) & 0.579 & 0.470 & 0.628 & 0.610 & 0.635 \\
\hline Rasio apoA-1/HDL-C & 3.02 & 0.22 & 3.24 & 0.23 & 0.001 \\
\hline Rasio CETP/HDL-C & 0.066 & 0.407 & 0.084 & 0.482 & 0.001 \\
\hline Rasio CETP/TG & 0.015 & 0.04 & 0.016 & 0.02 & 0.545 \\
\hline
\end{tabular}

Notes: $\mathrm{WC}=$ waist circumference $; \mathrm{BMI}=$ body mass index $; \mathrm{SBP}=$ systolic blood pressure; $\mathrm{DBP}=$ diastolic blood pressure; $\mathrm{HDL}=$ high-density lipoprotein; FBG= fasting blood glucose; ApoA-1 = apolipoprotein A1; Prebeta-1 HDL= prebeta-1 high-density lipoprotein; LCAT = lecithin cholesterol acyl transferase; CETP= cholesteryl ester transfer protein. PAl-1= plasma activated inhibitor-1; TG= triglyceride; Kruskal Wallis $\mathrm{H}$ test and 1 Independent sample T Test $(\mathrm{p}<0.05)$. 
Table 2 shows that F2-isoprostane did not have correlation with HDL biogenesis factors.
Table 3 shows significant correlations between serum PAI-1 with apoA-1/HDL-C ratio ( $r s=0.226 ; p=0.005)$ and CETP/TG ratios $\left(r_{\mathrm{s}}=-0.215 ; \mathrm{p}=0.007\right)$.

Table 2. Correlation between independent variable (F2-isoprostane) with dependent variable (apoA-1, prebeta-1 HDL, CETP, apo A1/HDL-C, CETP/HDL and CETP/TG ratios)

\begin{tabular}{|c|c|c|c|}
\hline Independent variable & Dependent variable & $r_{s}$ & $\mathrm{p}$ \\
\hline \multirow[t]{6}{*}{ F2-isoprostane } & ApoA-1 & -0.044 & 0.581 \\
\hline & Prebeta-HDI & -0.007 & 0.934 \\
\hline & CETP & 0.033 & 0.680 \\
\hline & Apo A1/HDL-C & 0.027 & 0.734 \\
\hline & CETP/HDL-C & 0.045 & 0.636 \\
\hline & CETP/TG & 0.063 & 0.420 \\
\hline
\end{tabular}

Notes: ApoA-1=apolipoprotein A-1, CETP= cholesterol ester transfer protein, HDL=high density lipoprotein, TG= triglyceride, $r_{\mathrm{s}}=\mathrm{Spearman}$ correlation.

Table 3. Correlation between independent variable (PAl-1) with dependent variable (apoA-1, prebeta-1 HDL, CETP, apoA-1/HDL-C, CETP/HDL-C and CETP/TG ratio).

\begin{tabular}{|c|c|c|c|}
\hline Independent variable & Dependent variable & $r_{s}$ & p \\
\hline \multirow[t]{6}{*}{ PAl-1 } & ApoA-1 & -0.013 & 0.874 \\
\hline & Prebeta-HDI & -0.023 & 0.781 \\
\hline & CETP & -0.059 & 0.465 \\
\hline & Apo A1/HDL-C & 0.226 & 0.005 \\
\hline & CETP/HDL-C & 0.078 & 0.419 \\
\hline & CETP/TG & -0.215 & 0.007 \\
\hline
\end{tabular}

Notes: PAI-1= plasminogen activator inhibitor-1, apoA-1=apolipoprotein A-1, CETP= cholesterol ester transfer protein, $\mathrm{HDL}=$ high density lipoprotein, $\mathrm{TG}=$ triglyceride, $\mathrm{r}_{\mathrm{s}}=$ Spearman correlation. 


\section{Discussions}

The aim of this study was to find out the relationship between F2-isoprostane and PAI-1, which are markers of oxidative stress, and impaired fibrinolysis with impaired HDL biogenesis that cause low HDL-C concentration in MetS.

In this study, in addition to HDL biogenesis factors, such as apoA-1, prebeta- $1 \mathrm{HDL}$, and CETP, other parameters like apoA-1/HDL, CETP/HDL-C, and CETP/ TG ratios were also used. ApoA-1/HDL-C ratio indicated HDL maturation. The lower apoA-1/HDL-C ratio described means the maturation process was more effective and apoA-1/HDL-C ratio also indicated the quality of HDL-C efflux. In this study we found the average apoA-1/HDL ratio was higher in the group with concentration of HDL-C $<40 \mathrm{mg} / \mathrm{dL}$ as compared with the group with HDL-C concentration $\geq 40 \mathrm{mg} / \mathrm{dL}$, This may explains that HDL maturation was less effective in the concentration of lower HDL.

CETP/HDL-C and CETP/TG ratios indicated HDL catabolism. The higher CETP/HDL-C ratio indicated increased HDL catabolism, and conversely higher CETP/ TG ratio indicated decreased HDL catabolism. Factors that play an important role in the catabolism of HDL include CETP, which play a role in the process of exchange of cholesterol esters from HDL with triglycerides from VLDL, IDL, and LDL. CETP activity was also influenced by the level of triglyceride. In high triglyceride concentration, the exchange rate of triglycerides from TG-rich lipoproteins and cholesterol ester from HDL increased, and HDL which contains large amount of triglycerides would stimulate the activity of hepatic lipase (13). In this study, we found that the average CETP/HDL-C ratio was higher in the group with HDL-C concentrations $<40 \mathrm{mg} / \mathrm{dL}$ as compared with the group with HDL-C concentration $\geq 40 \mathrm{mg} / \mathrm{dL}$. Thus HDL catabolism is increased at ower HDL-C concentration. The average CETP/TG ratio did not show significant differences between the group with HDL-C concentration $<40 \mathrm{mg} / \mathrm{dL}$ and the group with HDL-C concentrations $\geq$ $40 \mathrm{mg} / \mathrm{dL}$.

F2-Isoprostan did not correlate significantly with HDL biogenesis factors. The results of this study was supported by previous studies conducted by Hansel et al. who reported that the decline in anti-oxidant properties of HDL-C in MetS subjects was found along with decreased enzyme activity and changes in properties of HDL psicochemical. Thus, this may explain that the intrinsic nature of HDL particles is affected more than the concentration of cholesterol ester contained in HDL $(9,14)$. Thus the existence of oxidative stress in MetS subjects is more related to anti-oxidant capacity of HDL compared with the concentration of HDL cholesterol ester.

Previous studies have found that the decrease in antioxidant activity in small dense HDL correlated with the changes in the nature of psicochemical HDL particles rich in triglycerides and poor in cholesterol ester. The relationship between TG-rich HDL particles and impaired antioxidant activity can be explained by the evidence that TG-rich HDL particles changes in conformational central and C-terminal domain of apoA-1, which play an important role in the process of lipid acceptor. In MetS subjects, the small dense HDL comprises HDL3a, HDL3b, HDL3c subfractions which have lower anti-oxidant activity than the controls. In other studies it was also shown there was no significant difference in the amount of apoA-1 contained in HDL subfraction between MetS subjects and the controls, but the oxidative modification of apoA-1 in MetS subjects was due to oxidative stress (9).

In this study, we found no significant correlation between impaired fibrinolysis (PAI-1) and level of apoA-1, prebeta-1 HDL, and CETP, but PAI-1 levels correlated positively with apo A1/HDL-C ratio and negatively correlated with CETP/TG ratio. This shows that the state of impaired fibrinolysis causes decreased HDL maturation and increased HDL catabolism, this in turn will cause the formation of small dense HDL. This study agrees with a previous study that has found high concentrations of D-dimer and PAI-1 occured in patients with low HDL concentration (8).

In this study, we also found a significant correlation between PAI-1 and HOMA-IR $\left(r_{\mathrm{s}}=0.378 ; p<0.001\right)$. This study was in accordance with a previous study that has reported that obesity was often associated with insulin resistance and fibrinolytic system dysfunction (8) and central obesity as a promoter of MetS which characterized by impaired fibrinolysis, hypertension, dyslipidemia, and insulin resistanve states (15). Besides the role in atherothrombosis, PAI-1 was involved in the development of adipose tissue in insulin resistance. An interventional study has reported that when insulin sensitivity improved, this would decrease the level of PAI-1 (15). The mechanism by which PAI-1 in MetS subjects influences HDL biogenesis is suggested to be the same route as in insulin resistance.

In previous studies it was reported that the concentration of apoA-1 did not differ between subjects with insulin resistance and the control, but in the early stage of insulin resistance there occured significant changes in the metabolism of apoA-1, thus increased apoA-1 catabolism by $50 \%$. Fraction catabolic rate (FCR) 
apoA-1 was significantly positively correlated with waist circumference and HOMA-IR and in subjects with insulin resistance increased catabolism of apoA-1 as compraed with the controls. Increased apoA-1 catabolism would lead to significant reduction in the residence time of apoA-1 in plasma, although statistically showed no differences in apoA-1 production rate in subjects with insulin resistance as compared with the control. This may explain why concentration of apoA-1 in the plasma did not differ significantly between obese subjects and the controls. HDL-C was significantly negatively correlated with FCR apoA-1, but not with apoA-1 production rate. This may explain that the speed of apoA-1 catabolism was a very important factor in the decline in HDL-C concentration in subjects with insulin resistance. Insulin resistance correlated with decreased activity of lipoprotein lipase. TG-rich HDL is a good subtrated for hepatic lipase, thus increases HDL catabolism. Increased CETP activity was reported in subjects with insulin resistance and was thought as an important factor that plays a role in HDL catabolism $(16,17,18)$. In this study we also found high concentration of triglycerides $(202.08 \pm 105.34 \mathrm{mg} / \mathrm{dL})$.

Understanding of the mechanism linkages of F2isoprostane and PAI- 1 with the factors involved in HDL biogenesis are expected to be able to enrich the information for developing strategies to increase HDL-C concentration, in an attempt to reduce the morbidity and mortality rates of vascular disease.

\section{Conclusions}

Concentration of F2 isoprostane did not have correlation with the levels of HDL biogenesis factors. Oxidative stress in MetS subjects may be more related with the anti-oxidant capacity of HDL as compared with the levels of HDL cholesterol esters.

Impaired fibrinolysis in MetS subjects, represented by PAI-1, was correlated positively with apo A1/HDL-C ratio (HDL maturation) and correlated negatively with the CETP/TG ratio (HDL catabolism), these may lead to low HDL-C concentration in men with metabolic syndrome.

\section{Acknowledgements:}

We thank the Prodia foundation of Research and Training for their invaluable help in conducting the many procedures of this research.

\section{References:}

1. Ashen MD, Blumenthal MD. Low HDL-cholesterol concentrations. N Engl J Med 2005; 353: 12521260.

2. Lewis GF, Rader DJ,. New insights into the regulation of HDL metabolism and reverse cholesterol transport. Circ Res 2005; 96: 1221-1232.

3. Fredenrich A, Bayer P. Reverse cholesterol transport, high-density lipoprotein and HDL-cholesterol: Recent data. Diabetes Metab 2003; 29: 201-205.

4. Barter PJ, Brewer Jr HB, Chapman MJ. Cholesteryl ester transfer protein. A novel target for raising $\mathrm{HDL}$ and inhibiting atherosclerosis. Atheroscler Thromb Vasc Biol 2003; 23: 160-167.

5. Deen D. Metabolic Syndrome: Time for action. Am Fam Physician 2004; 69: 2875-2882, 2887-2888.

6. Tang W, Hong Y, Province MA, et.al. Familial clustering for features of the metabolic syndrome. Diabetes Care 2006; 29: 631-636.

7. Survey Kesehatan Nasional, Survey Kesehatan Rumah Tangga (SKRT). 2004. Badan Penelitian dan Pengembangan Depkes RI, Jakarta; 2004.

8. Tawakol R. High density lipoprotein cholesterol - The next battle front in the fight against heart disease. Business briefing: US Cardiology 2004: 1-3.

9. Hansel B, Giral P, Nobecourt E, et.al. Metabolic syndrome is associated with elevated oxidative stress and dysfunctional high-density liporotein particles displaying impaired antioxidative activity. J.Clin Endocrinol Metab 2004; 89: 4963-4971.

10. Alberti KG, Zimmet P, Shaw J. IDF epidemiology task force consensus group: The metabolic syndrome: a new worldwide definition. Lancet 2005; 366: 10591062.

11. Friel JP. Dorland's illustrated medical dictionary 26 th Ed. W.B. Saunders Company Philadelphia. 1981.

12. Lawrence GS. Interaksi asam lemak bebas, status anti oksidan total, plasminogen activator inhibitor-1, adiponektin, dan high sensitivity C-reactive protein terhadap kajian toleransi glukosa terganggu. Disertasi S3 Program Pascasarjana UNHAS. Makassar; 2004.

13. Parini P, Rudel LL. Is there a need for cholesteryl ester transfer protein inhibition? Atheroscler Thromb Vasc Biol 2003; 23:374-375.

14. Kontush A, Chapman J. Functionally defective highdensity lipoprotein: A new therapeutic target at the crossroads of dyslipidemia, inflammation, and atherosclerosis. Pharmacol Rev 2006; 58 : 342374.

15. Skurk T, Hauner H, Obesity and impaired fibrinolysis; Role of adipose production of plasminogen activator inhibitor-1. Int J Obes. 2004; 28: 1357-1364. 
16. Pont F, Duvillard L, Florentin E, Gambert P, Verges B, High density lipoprotein apolipoprotein A-I kinetics in obese insulin resistant patients. An in vivo stable isotope study. Int J Obes. 2002; 26: 1151-1158.

17. Chan DC, Barrett PH, Watts GF, Recent Studies of lipoprotein kinetics in the metabolic syndrome and related disorders, Curr Opin Lipidol. 2006; 17: 2836.

18. Chan DC, Barrett PH, Watts GF, Lipoprotein transport in the metabolic syndrome: Pathophysiological and interventional studies employing stable isotop and modelling methods. Clin Sci. 2004; 107: 233-249. 